\title{
Seasonal Changes of sandflies: A study of the Endemic Outbreak of Leishmania Major in Zagora, Southeast Morocco
}

\author{
Zalalham Al-Koleeby ${ }^{1}$, Ahmed El Aboudi ${ }^{1}$, and Chafika Faraj ${ }^{1}$. \\ ${ }^{1}$ Plant and Microbial Biotechnology, Biodiversity and the Environment, Faculty of Science, Agdal, Mohammed V University, Rabat, \\ Morocco. \\ ${ }^{1}$ Laboratory of Medical Entomology, National Institute of Hygiene, Rabat, Morocco.
}

\begin{abstract}
Leishmaniasis is endemic in the province of Zagora and presents a real danger to the health situation. It is manifested by endemic morbidity. The objective of this study is to assist in vector control measures by providing information on the richness, abundance, seasonal trend, presence and sex ratio of sand fly species in this active epidemic. The study was conducted in Bleida locality in the province of Zagora, during an outbreak of L. major. The results of this study, undertaken in 2019, showed the predominance of $\mathrm{Ph}$. papatasi $(44.8 \%)$, followed by $\mathrm{Ph}$. longicuspis $(26.3 \%)$ and S.schwetzi(8.2\%).The analysis supports the involvement of P. papatasi as a vector of L. major in Bleida locality. which indicates the increase of cutaneous leishmania in the province of Zagora.
\end{abstract}

\section{Introduction}

Leishmaniasis in Morocco is a developing public health problem. According to the Moroccan Ministry of Public Health, it was reported that between 2017 and 2018 in Zagora there were about (4402)cases of cutaneous leishmaniasis (CL), caused by Leishmania major[1]. Beside new foci have been identifed in some nonendemic areas, mainly in Tinzouline, in the southern Marocco where its unique vector, $\mathrm{Ph}$. papatasi and its reservoir host, Meriones shawi [2] .Ph. papatasi has been reported in almost all previous studies carried out in Morocco with various levels of prevalence. [3-6].This article presents the results of an entomological survey carried out in a CLZ focus in Zagora Province, Morocco, with the aim of the describing diversity of the sand fly fauna. The aim is also to specify the periods when their prevalence is high, and their ecology. The area of Zagora should be regarded as a big focus for L. major. This suggests the need for a continuously surveillance and preparation for a successful antivectorial program.

\section{Materials and Methods}

\subsection{Study area}

The study was conducted in Blieda locality in Zagora Province of Morocco (Fig. 1). The Climate in Zagora is very arid; with monthly mean high and low temperatures ranging from 32.3 to $4.4 \mathrm{C}$ in July and January, respectively. The average annual rainfall is $61 \mathrm{~mm}$. The province covers an area of $23000 \mathrm{~km}^{2}$ with altitude ranging $724 \mathrm{~m}$ above sea level. The topography is rugged and the vegetation is more diversited (Palm trees, almond, and carob trees). The total population is 52168 inhabitants, composed mainly of farmers almost all the houses in the village are made of mud, which is a perfect breeding site for sand flies.

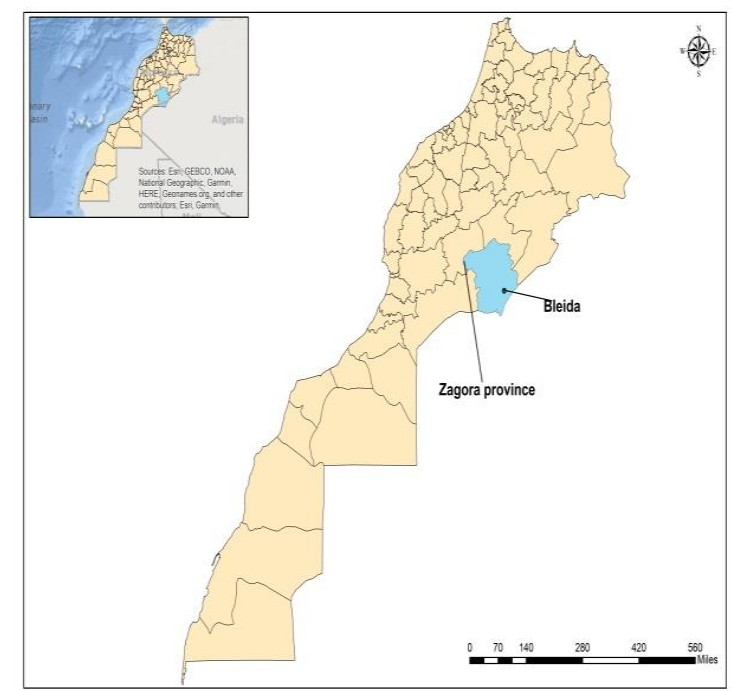

Fig. 1. Map showing the location of the study site.

\subsection{Sand flies collection and identification}

By using light traps, sandflies were captured in five homes that were randomly chosen from each of the homes investigated over the period of May to October 2019 .The light traps (CDC miniature battery-operated), 
were installed inside and outdoors homes. Two CDC tarps were set bimonthly, for four whole nights, from sundown to sunrise, in the same place, and in each home. The collected Sand flies were taken with a brush, then stored in tubes containing $96 \%$ ethanol. During the analysis in the laboratory, sand flies were cleared in Marc-Andre solution then fixed in microscopic slides for identification by examining the genitalia structure of males, spermathecae and pharynges of female following morphological keys [7] .

\section{Results}

A total of (2026) sand flies were caught. Eight species were identified as Phlebotomus genus (75.72\%) and seven as Sergentomyia genus $(24.28 \%)$. The anatomic analysis of males species show a higher number of females $(88,89 \%)$ while females species show a less number of males $(11.11 \%$ ) (as shown in table1) For the genus of Phlebotomus, P. ( phlebotomus) papatasi was the most dominant by $44,82 \%$ followed by $P$. (Larroussius) longicuspis were represented with $26,31 \%$.These two species account for $(71.13 \%)$ of all sand flies captured in this study. While, P. (phlebotomus) bergeroti and P. (Larroussius)chabaudi were represented with(1.88\%) and (1.43\%) respectively. While (Paraphlebotomus)alexandri, (Paraphlebotomus) sergenti, (Larroussius) longeroni and Ph. kazeruni(Paraphlebotomus) were weakly represented $(0.59 \%),(0.49 \%),(0.15 \%),(0.05 \%)$.In Sergentomyia , the predominant specie was S. (Sergentomyia). schwetzi which represented $(8.19 \%)$ of the total sand flies collected, followed by S. (Parrotomyia) africana $(7.06 \%)$, S. (Sergentomyia) fallax $(5.28 \%)$ followed by(Sintonius )clydei (2.02\%),S(grassomyia) dreyfussi $(0.84 \%)$ S. (Sergentomyia) minuta (0.64\%), S. (Sergentomyia) antennata $(0.25 \%)$. Compositing Sand fly showed biodiversity among different sampling houses. (See Table 1).

Table1. Sand fly species collected in Bleida locality and their relative abundance $(\%)$.

\begin{tabular}{|l|c|c|c|c|}
\hline & \multicolumn{4}{|c|}{ Bleida } \\
\hline & \multicolumn{3}{|c|}{ ABUNDANCE } & frequency \\
\hline SPECIES & M & F & Total & $\%$ \\
\hline Ph. papatasi & 700 & 208 & 908 & $44.82 \%$ \\
\hline Ph.longicuspis & 395 & 138 & 533 & $26.31 \%$ \\
\hline Ph. bergeroti & 4 & 34 & 38 & $1.88 \%$ \\
\hline Ph. chabaudi & 29 & 0 & 29 & $1.43 \%$ \\
\hline Ph.alenxandri & 8 & 4 & 12 & $0.59 \%$ \\
\hline Ph. sergenti & 9 & 1 & 10 & $0.49 \%$ \\
\hline Ph. longeroni & 0 & 3 & 3 & $0.15 \%$ \\
\hline Ph. kazeruni & 0 & 1 & 1 & $0.05 \%$ \\
\hline S. schwetzi & 147 & 19 & 166 & $8.19 \%$ \\
\hline S . africana & 86 & 57 & 143 & $7.06 \%$ \\
\hline S . fallax & 30 & 77 & 107 & $5.28 \%$ \\
\hline S. clydei & 20 & 21 & 41 & $2.02 \%$ \\
\hline S. dreyfussi & 2 & 15 & 17 & $0.84 \%$ \\
\hline S . minuta & 3 & 10 & 13 & $0.64 \%$ \\
\hline S. antennata & 0 & 5 & 5 & $0.25 \%$ \\
\hline Total & 1433 & 593 & 2026 & $100.00 \%$ \\
\hline
\end{tabular}

The biodiversity indexes reached in the village of Bledia $(\mathrm{H}=1.63)$, can be linked to the predominance of $\mathrm{Ph}$. papatasi. The richness in Bleida was found in fifteen species. Sand flies were active especially from May to October (Figure 2), peaked up in May , then dropped remarkably in June and July, to disappear in November. The males $(r=0.3)$ were more than females.

\section{Discussion}

This investigation is a survey of the abundance of sand flies in Bleida locality of Zagora province .The focus was on endemic type of ZCL. In Morocco, 23 species of sandflies have been detected so far, which include 14 species belonging to the genus Phlebotomus and 9 to the genus Sergentomyia .IN an entomological survey in Bleida, thirteen species of sandflies were identified during the period May-October (2019).Of the thirteen species captured, eight belonged to the genus Phlebotomus and seven to the genus Sergentomyia. The genus Phlebotomus includes three different subgenera: Phlebotomus, Larroussius and Paraphlebotomus .In the subgenus Larroussius, we have recorded two species: $\mathrm{Ph}$. Longicuspis and $\mathrm{Ph}$. Longeroni the first is the proven vector of L. infantum [8]. In the subgen Paraphlebotomus, we have found four species: $\mathrm{Ph}$. Alexandri, Ph. Sergenti, Ph. Kazeruni and Ph. Chabaudi. The second is the confirmed vector of L. tropica in Morocco [9]Ph. Papatasi andPh.bergeroti were the unique species belonging to the Phlebotomus subgenus in our collection. Papatasi is the established vector of L. major in Morocco [10]. The seven species belonging to the genus Sergentomyia (Se. schwetziSe. clydei S. minuta, S.fallax, Se. africana S. antennata and S. dreyfusi), had low representation from phlebotomus(24.28\%) [11, 12] According to our results, the time period of phlebotomous activity was throughout the year. The highest frequency of P. Papatasi, as the main vector of ZCL, in Zagora was recorded in May and July 2019 . In the opinion of many researchers, this season is characterized by the greatest phlebotomous growth $[13,14,15,16]$. . Ph. Papatasi, was collected in the village where it was the largest phlebotomus caught, representing (44.82\%) of the total number of specimens. $\mathrm{Ph}$. papatasi was reported to be a sub-Saharan vector. It is the most widely collected species in arid and per arid zones $[17,18,19$,20].The spread of Ph. Papatasi appears to be mostly determined by bioclimate. In Bleida, where it is abundant, $\mathrm{Ph}$. Papatasi populations were most prevalent from May to October with twopeaks. These values are consistent with previous studies in Marrakech region in southwest Morocco [21 ]. which supports its large distribution in the village its adaptation to various climates and its tolerance to the environment and high temperatures [22].Ph. Longicuspis showed a bimodal annual abundance model with two peaks in May and Augest in Bleida locality(Fig. 2). The long activity period of $\mathrm{Ph}$. Longicusp and its large distribution cause worry and reflects the potential risk of high transmission of L.infantum in the village of Bleida. Ph. longicuspis was abundant in the Bleida locality at an altitude of 611 
$\mathrm{m}$. Ph. Sergenti is proven to be a vector of L. tropica in the north of Morocco [23]. In this area of study, $\mathrm{Ph}$. Sergenti was found to be less widespread $(0.49 \%)$; in (Bleida locality). These results may help explain the observed increase in ACL incidence in Morocco and its diffusion to new non-endemic regions as (Bleida). The appearance and abundance of species in Morocco seems to be more influenced by climate and abiotic factors[24,25], especially in areas with poor housing conditions .Moreover, the establishment of animal colonies close to households plays a role in the transmission of leishmaniasis. Based on the results, it can be deduced that the improvement of human houses and the isolation between animal and human dwellings could be an important step to eliminate sand flies. The results of this study showed the seasonal trends of the most important sandflies vectors that could be useful to predict the area and timing of the highest risk of leishmaniasis transmission.

\section{Conclusion}

The presence of $\mathrm{P}$. papatasi was very large in Zagora all year round. In accordance with the spread of zoonotic cutaneous leishmaniasis epidemics in Bleida locality, the presence of $\mathrm{P}$. papatasi should be considered as an outbreak for L. major. This suggests the necessity of continuous surveillance to prevent the dangers of leishmaniasis.

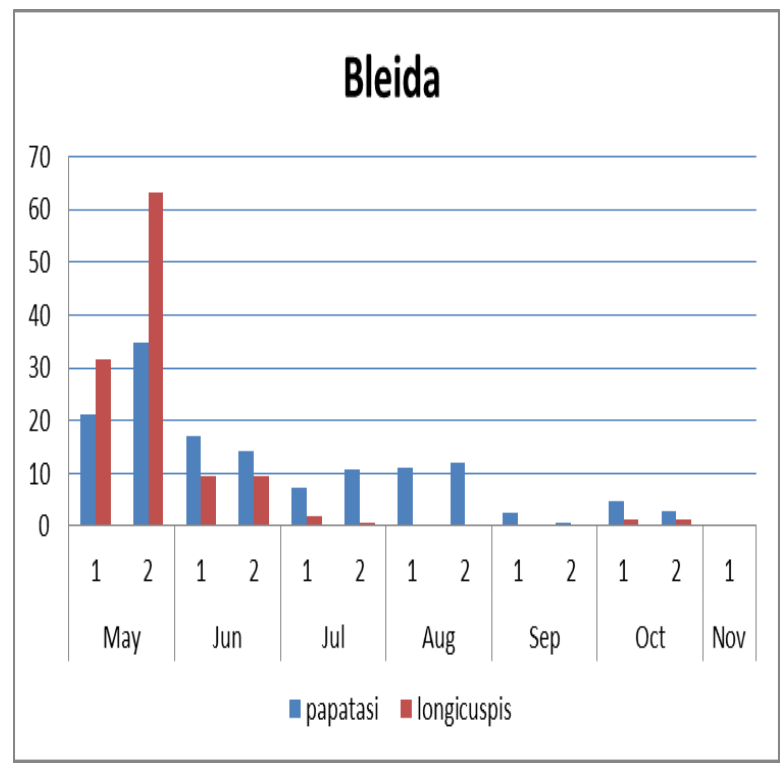

Fig. 2. Bimonthly capture records for sand flies in Bleida locality.

Acknowledgements. The authors gratefully thank the staff of the medical delegations of Zagora for their great assistance in the field research. In addition, they would like to thank Souhail Aboulfadl ,Lakraa El Housseine, Elkohli Mohammed, Karima El Mouhdy and Othmane Trimasse for their valuable contribution to the identification of sandflies.

\section{References}

1. A .El Hamouchi, O .Daoui, M .Ait Kbaich, I .Mhaidi, S .El Kacem, I. Guizani, et al. Epidemiological features of a recent zoonotic cutaneous leishmaniasis outbreak in Zagora province, southern Morocco. PLoS Negl Trop Dis 13(4): e0007321. (2019)https://doi.org/10.1371/journal. pntd.0007321

2. JA. Rioux, F .Petter, O .Akalay. G .Lanotte, A .Ouazani, M .Seguignes, et al. Meriones shawi (Duvernoy, 1842) (Rodentia, Gerbillidae). réservoir de Leishmania major Yakimoff et Shokhor, 1914 dans le Sud Marocain. C R Seances Acad Sci III. 1982;294(11):515-517(1982).

3. H. Bailly-Choumara, E. Abonnec .\& J .Pastre . (1971). Contribution to the study of sand flies of Morocco (Diptera, Psychodidae). Faunistic and ecological. (1971).

4. N .Guessous-Idrissi, S .Chiheb, A .Hamdani, M .Riyad, A .Bichichi. \& A. .Krimech. Cutaneous leishmaniasis: an emerging epidemic focus of Leishmania tropica in north Morocco. Transactions of the Royal Society of Tropical Medicine \& Hygiene 91, p. 660-663. (1997a).

5. M. El Alem, M. Hakkour, A .Hmamouch et al. Risk factors and prediction analysis of cutaneous leishmaniasis due to Leishmania tropica in Southwestern Morocco, Infection, Genetics and Evolution, vol.61,pp. 84-91. (2018).

6. C. Faraj, E.B. Adlaoui, S. Ouahabi, M .El Kohli, M. El Rhazi, L. Lakraa. \& B.Ameur. Distribution and bionomic of sand flies in five ecologically different cutaneous leishmaniasis foci in Morocco. Parasites \& Vectors 6, p. 334-342. (2013)

7. C Faraj, O .Himmi. Clés morphologiques pour l'identification des phlébotomes du Maroc (Diptera: Psychodidae: Phlebotominae). Bull. Soc. Pathol. Exot. (In press) (2020)

8. J. A. Rioux, G. Lanotte, F. Petter et al., "Les leishmanioses cutanées du bassin Méditerranéen occidental, de l'identification enzymatique à l'analyse éco-épidémiologique. L'exemple de trois "foyers", tunisien, marocain et français," in Leishmania.Taxonomie et Phylogenèse. Applications Eco-Epidémiologiques, pp. 2365-6395, Colloque International CNRS/INSERM/OMS, Institut Méditerranéen d'Etudes Epidemiologiques et Ecologiques, Montpellier, France, (1986).

9. E. Guilvard, J. A. Rioux, M. Gallego et al., "Leishmania tropica in Morocco. III-The vector of Phlebotomus sergenti. Apropos of 89 isolates," Annales de Parasitologie Humaine et Comparee, vol. 66, no. 3, pp. 96-99, (1991).

10. J. A. Rioux, E. Guilvard, J. Dereure et al., "Infestation naturellede Phlebotomus papatasi (Scopoli, 1786) par Leishmania major MON-25. A propos de 28 souches isolées dans un foyer du Sud Marocain," in Leishmania. Taxonomie et 
Phylogenèse. ApplicationsEco-Epidémiologiques, pp. 2471-6480, Colloque InternationalCNRS/INSERM/OMS, Institut Méditerranéen d'Etudes Epidemiologiques et Ecologiques, Montpellier, France, 1986.

11. S. Boussaa, B. Pesson, and A. Boumezzough, "Faunistic study of the sandflies (diptera: Psychodidae) in an emerging focus of cutaneous leishmaniasis in Al Haouz province, Morocco," Annals of Tropical Medicine and Parasitology, vol. 103, no. 1, pp. 73-83, (2009).

12. M, Zouirech M,D,Belghyti and C, Faraj. Entomological and epidemiological investigations of an emerging focus of cutaneous leishmaniasis in Bzou, Morocco, Entomologie Faunistique. vol. 68, pp. 201-211. ( 2015).

13. K. Ramaoui, S. Guernaoui, and A. Boumezzough, "Entomological and epidemiological study of a new focus of cutaneous leishmaniasis in Morocco," Parasitology Research, vol. 103, no. 4, pp. 859863,(2008).

14. S. Guernaoui, A. Boumezzough, and A. Laamrani, "Altitudinal structuring of sand flies (Diptera: Psychodidae) in the High- Atlas mountains (Morocco) and its relation to the risk of leishmaniasis transmission," Acta Tropica, vol. 97, no. 3, pp.346-351, (2006).

15. S .Guernaoui, A Boumezzough, B .Pesson, G Pichon. Entomological Investigations in Chichaoua: An Emerging Epidemic Focus of Cutaneous Leishmaniasis in Morocco. J. Med. Entomol. 42 (4): 697-701. (2005).

16. J .Ghrab. A .Him, D.Bach-Hamba, M.K.Chahed, K.Aoun, S Aouira. \& A .Bouratbine. Phlebotominae (Diptera: Psychodidae) of human leishmaniasis sites in Tunisia. Parasite 13, p. 23-33(2006).

17. J. A. Rioux, O. Akalay, J. Périères et al., "L'évaluation écoépidémiologisquedu "risque leishmanien" au Sahara atlantique marocain. Intérêt heuristique de la relation 'phlébotomesbioclimats,', Ecologia Mediterranea, vol. 23, pp. 73-92, 1997.

18. J. A. Rioux, P. Rispail, G. Lanotte, and J. Lepart :, "Relations Phlébotomes-bioclimats en écologie des leishmanioses Corollaires épidémiologiques. L'Exemple Du Maroc," ActualitésBotaniques, pp. 549-557, (1984).

19. F. M. Simsek, B. Alten, S. S. Caglar et al., "Distribution and altitudinal structuring of phlebotomine sand flies (Diptera: Psychodidae) in southern Anatolia, Turkey: their relation to human cutaneous leishmaniasis," Journal of Vector Ecology, vol.32, no. 2, pp. 269-279, 2007

20. S. Boussaa, M. Neffa, B. Pesson, and A. Boumezzough, "Phlebotomine sandflies (Diptera: Psychodidae) of southern Morocco: results of entomological surveys along the MarrakechOuarzazat and Marrakech-Azilal roads," Annals
ofTropical Medicine and Parasitology, vol. 104, no. 2, pp. 163-170,(2010).

21. S. Boussaa, S. Guernaoui, B. Pesson, and A. Boumezzough, "Seasonal fluctuations of phlebotomine sand fly populations (Diptera: Psychodidae) in the urban area of Marrakech,Morocco," Acta Tropica, vol. 95, no. 2, pp. 86-91, (2005).

22. C. Sauvage, "Etages bioclimatiques au Maroc," in Atlas du Maroc, vol. 1, p. 44p, Inst SC Chérif, Rabat, Morocco, (1963).

23. F. Pratlong, J. A. Rioux, J. Dereure et al., "Leishmania tropica inMorocco. IV-Intrafocal enzyme diversity," Annales de Parasitologie Humaine et Comparee, vol. 66, no. 3, pp. 100-104, (1991).

24. J. A. Rioux, "Trente ans de coopération francomarocaine surles leishmanioses: dépistage et analyse des foyers. Facteurs. de risque. Changements climatiques et dynamique nosogéographique," Association des Anciens ELèves de L'Institut Pasteur, vol. 168, pp. 90-101, (2001).

25. ER .Cross, WW .Newcomb, CJ .Tucker. Use of weather data and remote sensing to predict the geographic and seasonal distribution of Phlebotomus papatasi in southwest Asia. Am. J. Trop. Med. Hyg. 54(5):530-536. (1996). 